\title{
Gestión del proceso de evaluación del desempeño docente: desde la administración de la educación
}

\author{
Management of the process of evaluation of teacher performance: from the Educational Management
}

\author{
Marianela Ugalde Vega' \\ Docente, Ministerio de Educación Pública \\ marianelaugaldevega@yahoo.es
}

Recibido 20 noviembre 2011 • Aceptado 14 diciembre 2012 • Corregido 16 de diciembre 2012

\begin{abstract}
Resumen. El presente estudio se llevó a cabo en las organizaciones educativas: Escuela Barrio Limoncito y la Escuela los Lirios del Circuito Escolar 02 de la Dirección Regional Educativa de Limón en San José Costa Rica, cuyo objetivo general es analizar la gestión del proceso de evaluación del desempeño docente en estos centros educativos del Ministerio de Educación Pública. Es un estudio fundamentado en el enfoque descriptivo, se sustenta en técnicas metodológicas mixtas: cualitativas y cuantitativas. Dentro de las organizaciones educativas se consulta al personal docente y personal administrativo, donde se destacaron entre los principales hallazgos que los procesos de la evaluación del desempeño son fundamentales para mejorar el desarrollo del desempeño docente en busca de la calidad de la educación que se imparte. Es indispensable contar con adecuados procesos desde la gestión de las organizaciones educativas que permitan fortalecer estos procesos.
\end{abstract}

Palabras clave. Administración de la educación, evaluación del desempeño docente, desempeño docente, gestión de la educación y educación.

Abstract. This study was conducted in the educational organizations: Barrio Limoncito School and los Lirios School from the School District 02 of the Regional Educational Administration of Limon in Costa Rica, whose general objective is to analyze the managing process of teacher evaluation on these schools from the Ministry of Education. It is a study based on the descriptive approach. It is based on mixed methodological techniques: qualitative and quantitative. Within the educational organizations teachers and administrative staff are consulted, and among the main findings, it was found that the processes of the evaluation of performance are fundamental to improve the development in teacher performance in search of the quality of the education provided. It is essential to have adequate management processes from educational organizations that strengthen these processes.

Keywords. Education management, teacher performance evaluation, teacher performance, education management and education.

\footnotetext{
Magíster en Ciencias de la Educación con énfasis en Administración Educativa de la Universidad de Costa Rica (UCR). Bachiller y Licenciada en Ciencias de la Educación con énfasis en I y ll Ciclos de la Educación General Básica. Actualmente se desempeña como docente para el Ministerio de Educación Pública, en la provincia de Limón, Costa Rica.
} 


\section{Introducción}

En la actualidad, la sociedad experimenta importantes cambios sociales, económicos, políticos y culturales, siempre en busca de la perfección humana como ser integral en un entorno que se encuentra en constante cambio a nivel mundial, ya que los países que cuentan con la mejor mano de obra profesional son los más desarrollados en todos los campos, especialmente en educación.

El sistema educativo requiere que personal directivo encargado de la gestión conduzca las organizaciones, en forma eficiente y eficaz, ante los complejos retos sociales y económicos, como consecuencia de las exigentes demandas derivadas de la sociedad globalizada. La capacidad de aprendizaje, la destreza laboral y la competencia personal entre el personal docente es estratégica, en medio de una sociedad económicamente demandante que espera en los profesionales de la, adecuados procesos de enseñanza-aprendizaje, de manera que se incida en la formación integral de los individuos, con adecuadas competencias que lo preparen para ser una persona productiva ante una sociedad que exige excelencia, tal y como lo consideran Delors, Mufti, Amagi, Carneiro, Chung, Geremek y Nanzhao (1996), cuando mencionan que "los sistemas educativos deben responder a los múltiples retos que les lanza la sociedad de la información, en función siempre de un enriquecimiento continuo de los conocimientos y del ejercicio de una ciudadanía adaptada a las exigencias de nuestra época" (p. 33).

Hoy en día, la sociedad exige ajustar el actuar del ser humano a un conjunto de normas y procederes que mantengan un ambiente agradable y que todo lo que se produzca sea para beneficio de la sociedad civil, con un enfoque inclusivo. La sociedad necesita o espera, que el personal docente desarrolle un pensamiento crítico, analítico y creativo, de manera que su desarrollo intelectual sirva en beneficio para el servicio de las instituciones sociales, en general.

Al respecto, Romero (2004) considera que "la sociedad del conocimiento pone a la cultura escolarizada ante la alternativa de cambiar los principios de su lógica moderna de producción o estelar" (p.21). La sociedad, en su variedad del pensamiento, propicia la formación de personas razonables y decididas a tomar decisiones, ante lo cual el sistema educativo tiene un papel fundamental, en el que el personal docente, en su labor diaria, desarrolla diariamente bienestar, oportunidad, destrezas y otros que enseñan al ser humano a enfrentar los cambios de la democracia social, hacia la globalización.

La educación, por tanto, se desenvuelve en una constante variable profesional, provocadora de ansias de aprender y enseñar, de manera que los individuos puedan integrase de forma rápida a su entorno. Así, la educación debe establecer su proceso, reestructurando los modelos y sistema de organización, para que responda a los nuevos desafíos que la sociedad del conocimiento exige, desde lo epistemológico, pedagógico y didáctico. Para Romero (2004), 
estas áreas abarcan el proceder educativo en cualquier sistema de formación abierta, lo que involucra que su revisión dependa del nivel de estudio e indagación que se realiza por medio de la evaluación institucional en todos sus espacios, tal y como se espera desde la sociedad del conocimiento, donde la centralidad de la educación proviene del hecho de ser la única variable de intervención política que incide en el desarrollo de la nación.

Las organizaciones educativas deben aprender a reflexionar ante los nuevos retos y las exigencias de la sociedad y el conocimiento de los individuos; el personal directivo de las organizaciones educativas, deberá cuidar que su personal se actualice constantemente, manteniendo deseos de realizar su trabajo con rectitud, conservar el interés docente, ser mejor cada día y brindar un servicio de calidad.

La administración de la educación en su actuar, presenta distintos desafíos, por lo que debe adaptarse a cambios constantes. El personal directivo de la educación mediante la creatividad debe mantener un ambiente innovador que involucre al personal docente y a la población estudiantil, incrementando la acometividad entre ellos, un pensamiento reflexivo, a partir de un ambiente sano y creativo.

De ahí, que uno de los criterios de la evaluación del desempeño docente es promover que las organizaciones educativas busquen la estructuralización idónea de crear, generar, gestionar y organizar un orden para garantizar su versatilidad y flexibilidad en el proceso y la producción del conocimiento de la evaluación del desempeño del personal docente en el ámbito educativo, todo ello tomando en cuenta las exigencias de la sociedad globalizada.

\section{Justificación del problema y su importancia}

El objetivo fundamental de la administración de la educación es brindar los mejores servicios educativos mediante la utilización apropiada de recursos y la planificación estratégica adecuada. Es indispensable, por ello, que el personal directivo de la educación conduzca la organización con altos niveles de eficiencia haciendo un uso adecuado de sus recursos, como lo consideran Chacón, Elizondo, Fernández, Triana y Umaña (2011):

(...) uno de los objetivos fundamentales de la administración de la educación es ofrecer los mejores servicios educativos, a través de una óptima utilización de recursos que la sociedad pone a su disposición, mediante la acción planificada de los objetivos organizacionales, es que se vuelve indispensable el papel del profesional en administración de la educación, porque los recursos humanos y materiales requieren de un adecuado desempeño, con el fin de contribuir con el logro satisfactorio de los objetivos. (p. 9) 
Lo anterior, evidencia que los centros educativos para ofrecer un servicio de calidad, deben mantener una planificación organizada del personal docente y administrativo en la educación, capaz de satisfacer las necesidades que tiene la población educativa con un adecuado desempeño docente para que se formen personas capaces de pensar, actuar y decidir. Es así, que la administración de los centros educativos es compleja, por lo que se necesitan personas preparadas en el campo de la administración para que lleven a cabo, con eficiencia y efectividad, las tareas en aras del cumplimiento de los objetivos planeados.

El personal directivo debe realizar sus funciones con un liderazgo que permita la funcionalidad y calidad de los procesos que se gestan. Sin embargo, las funciones y las habilidades son diversas, lo que requiere de un adecuado desempeño de los centros educativos, sustentado en la labor que realiza el personal docente y profesionales en administración de la educación.

De esta forma, la administración de la educación en relación con el personal docente, tiene la finalidad de velar por el desempeño óptimo que realizan en las aulas, en busca de lograr los objetivos y metas definidas por la institución, donde intervienen un conjunto técnicas para consolidar un buen equipo de trabajo; donde median una serie de factores que influyen en la formación del recurso humano. Actualmente, se presentan diferencias en relación con la evaluación del desempeño docente en los centros educativos públicos, lo que hace reflexionar sobre la ejecución de estos procesos.

Una de las claves para el mejoramiento de la calidad educativa, está en la eficiencia del desempeño del personal docente y el desarrollo de programas educativos y curriculares. Al respecto, Airasian y Gullickson (2000), se refieren al desempeño docente tomando en cuenta la percepción sobre la colaboración profesional, al mencionar que es importante "ayudar al profesorado a detectar y tomar decisiones sobre los puntos fuertes y débiles de su práctica con la intención de mejorar" (p. 14). Esto es fundamental, pues el propósito es ayudar en el desarrollo y productividad de los profesionales de la educación y al buen desempeño de su práctica pedagógica, siempre en busca del bien común, la buena práctica y desarrollo del conocimiento de la población estudiantil, facilitando la labor del personal directivo en la organización educativa, en su función de velar porque se cumplan los objetivos y fines de la educación costarricense.

En muchas ocasiones, se atribuye el fracaso o el triunfo de los centros educativos al buen o mal desempeño del personal docente; siendo necesario que el personal directivo cuente con herramientas adecuadas para evaluar el desempeño docente y adecuados procesos de gestión. Los instrumentos evaluativos para estos efectos, son importantes herramientas para un óptimo desempeño docente, tal como lo señalan Airasian y Gullickson (2000) al reconocer la participación del personal docente en su propio desarrollo profesional, su experiencia y sentido de mejorar las expectativas docentes, día a día. 
Por esta razón, es de suma importancia, desde la administración de la educación, realizar los procedimientos de gestión necesarios para lograr un adecuado desempeño docente y contar con mecanismos eficientes de evaluación al respecto, aportando al mejoramiento de la calidad de la educación que se imparte.

Es responsabilidad, en este contexto de la administración de la educación, velar por el adecuado desempeño profesional del personal docente que labora en las organizaciones educativas; tema que es ampliamente cuestionado en el sistema educativo, debido a que las evaluaciones que por normativa se aplican, en general, obtienen valoraciones de excelencia, independientemente de la calidad del profesorado. Esta situación podría generar desmotivación en el profesional docente y apatía por estos procesos que se aplican por un cumplimiento normativo, puesto que los resultados obtenidos en su aplicación no tienen un impacto en la calidad del centro educativo. Ante este contexto, el presente estudio se ha planteado como objetivo general analizar la gestión del proceso de evaluación del desempeño docente de la Escuela Barrio Limoncito y la Escuela los Lirios del Circuito Escolar 02 de la Dirección Regional Educativa de Limón. Los objetivos específicos son:

- Determinar el proceso de planificación empleado en la evaluación docente.

- Reconocer los mecanismos de coordinación empleada en la evaluación docente.

- Identificar estrategias de organización utilizadas en la evaluación docente.

- Describir los procedimientos empleados para el control del proceso de evaluación docente.

- Conocer los mecanismos de evaluación del proceso de evaluación docente.

- Determinar la pertinencia del proceso de evaluación docente aplicado.

- Identificar la utilidad que tiene la evaluación del personal docente en el mejoramiento de la calidad de la educación en los centros educativos escolares.

\section{Referente teórico}

\section{Educación}

El concepto de educación es ampliamente desarrollado por diferentes autores y corrientes teóricas, por lo que son variados los conceptos que enmarcan su explicación teórica. Al respecto, 
Gutiérrez (1982) presenta una conceptualización de la educación enfocada a la socialización, en la que se indica que "educar es por tanto socializar, preparar individuos para una sociedad concreta e ideológicamente definida" (p.15). La educación, por tanto, está comprometida a crear estímulo y control, sobre la capacidad humana para producirse y desarrollarse en una sociedad, con materiales organizados formal e informalmente, dentro de un sistema unificado, concebido para los objetivos establecidos.

De ahí, que la socialización es parte importante del proceso educativo; éste se lleva a cabo en la niñez, la adolescencia o adultez en el diario convivir con otras personas, en el proceso de la educación formal e informal, para desarrollarse como persona según la sociedad donde vive, conviviendo en armonía y manteniendo el respeto a las demás personas. Por ello, se considera un proceso de decisiones en las que intervienen recursos humanos, materiales, económicos y técnicos- pedagógicos necesarios para la organización de la educación.

Además, Fernández y Sarramona (1997) definen la educación como un proceso que realiza el ser humano para garantizar su desarrollo potencial e intelectual, en un sistema abierto o cerrado, desarrollando todas sus habilidades. Por otra parte, Argudín (2006) afirma que el ser humano vive una continua transformación durante el proceso de aprendizaje, siendo una ardua tarea para el profesional en educación, quien desarrolla todo el potencial de la población estudiantil, al considerar que:

(...) la educación se entiende como el proceso donde se realiza la unión de dos actividades: la enseñanza y el aprendizaje. Se puede definir la enseñanza como la acción del educador sobre los educandos (programada o no), esta tiende a transformar al alumno a partir de que este es capacitado. El aprendizaje es el resultado demostrable de la labor que realiza el alumno para adquirir instrucción. El ser humano tiene la capacidad de aprender y por eso puede ser educado. (p. 26)

Este afirma que la educación, en realidad, es la unión de la enseñanza con el aprendizaje, tendiendo a transformar al alumnado para que adquiera conocimiento o puedan pulir el que ya tienen. Otra definición de educación, se orienta hacia un proceso formal y social, donde el individuo interactúa con su entorno obteniendo un aprendizaje significativo, lo que procura desarrollar capacidades y valores que ayudan al fortalecimiento de las personas. Por ello, Salazar (1998) define la educación como: 
El proceso formativo permanente, que es inherente a la persona humana. Es el proceso social mediante el cual interiorizan situaciones de aprendizaje, cuyo producto final son las capacidades u valores que contribuyen al fortalecimiento de la capacidad de la vida humana personal y colectiva. (p. 14)

De ahí, que la educación es un proceso formativo por el cual las personas interiorizan todas las situaciones que ocurren a su alrededor, acumulan información, se capacitan en valores y fortalecen la capacidad de desenvolvimiento para el desarrollo individual y social.

\section{Administración de la educación}

La administración de la educación está ligada al trabajo de grupos organizados en el campo de la educación; es una acción sistemática, orientada por principios encauzados a la eficiencia del trabajo desempeñado por el personal docente o administrativo. La administración de la educación, proporciona trabajo y dinamismo en la institución, destinado a la promoción y formación integral del personal docente, lo que implica brindar una labor organizacional en el proceso, como lo indica Chiavenato (2006) al referir que "administrar es el proceso de planear, organizar, dirigir y controlar el uso de los recursos para los objetivos" (p.8). La administración de la educación es un proceso en el cual se comparten encabezamiento y ejecución de acciones, para obtener el máximo rendimiento posible. Por ello, es un proceso que debe ser dinámico y eficiente para el manejo adecuado del mejor y mayor uso de los recursos organizacionales. Es su proceso diario, de diferentes fases claramente determinadas hacia la acciones de la planeación, organización, dirección, supervisor, control e integración.

La percepción del concepto de administración de la educación permite articular y dinamizar el desarrollo social para hacer efectiva la acción directiva y así, operacionalizar las políticas educativas en los centros educativos, por lo que Garbanzo y Orozco (2007) definen este concepto de la siguiente manera:

La administración de la educación debe actuar articulada con las políticas públicas y hacer de la educación el eje dinámico del desarrollo social al que se aspira. La administración de la educación está llamado a hacer que se operacionalicen las políticas educativas; para ello requiere movilizar los recursos necesarios. (p. 109) 
La administración de la educación, por tanto, debe actuar en concordancia con las políticas educativas y necesidades que presenta el centro educativo, específicamente en relación con su población.

\section{Gestión de la educación.}

De acuerdo con Antúnez y Aranguren (1998), "la palabra gestión es actualmente una de las más utilizadas cuando se trata de describir o de analizar el funcionamiento de la institución escolar" (p. 59). El término gestión sugiere actuación, tiene siempre una dimensión dinámica y además, necesita ser acompañada de un referente, de una especificación que lo complemente. Es por eso que se refiere a la gestión de los recursos humanos, la gestión administrativa, gestión del paisaje, gestión del patrimonio, gestión del currículo, gestión económica, entre otros.

La expresión gestión, por sí misma, no sirve para explicar de manera suficiente y precisa el alcance de las actuaciones que representa. Habitualmente, se utiliza como una denominación genérica bajo la cual se agrupan más o menos, indiscriminadamente, conceptos diversos. Por su parte, Blank (1990) comenta que el trabajo del profesional en administración de la educación consiste, casi en su totalidad, en comunicarse, puesto que son emisores y receptores de información: "la comunicación es, la herramienta más eficaz que tiene un administrador para realizar su labor, pues esta comprende una red de comunicaciones; su superior, sus subalternos, con otros gerentes, otras organizaciones, otras personas de la comunidad" (p. 105). Los profesionales que ejercen la gestión en los centros educativos deben estar preparados para tener una fluidez en la comunicación con su personal, con el fin de que en la institución se hable el mismo idioma y que a la hora de desarrollar algunas estrategias, éstos puedan llevarse a cabo de la mejor manera.

En la gestión de la educación existen diferentes dimensiones para su operacionalización, una de ellas se refiere a los procesos, ya que considera que los métodos aplicados consisten en el conjunto de labores de planeamiento, organización, dirección de la ejecución, control y evaluación, necesarias para el eficiente desarrollo de acciones educativas.

Asimismo, Arana (1998) manifiesta que cuatro son los criterios para lograr una buena gestión de la educación:

Conducir las diversas acciones educativas para el logro de metas y objetivos, creando las condiciones necesarias para su cumplimiento.

Desarrollar una cultura democrática y eficiente con responsabilidades dentro de las escuelas, con autoridades que promuevan y potencien sistemas de participación y comunicación. 
Conseguir que cada uno de los miembros de la comunidad educativa cumplan con funciones parea lograr las metas y objetivos sobre los que han tomado acuerdos.

Evaluar tanto los procesos como los resultados del servicio educativo para identificar logros, deficiencias y soluciones creativas que la optimicen. (p. 75)

Este mismo autor, considera que hay necesidad de cambio en la administración de la educación, de tal forma que se coadyuve en la obtención de una educación con calidad. Un centro educativo bien gestionado, a pesar de la adversidad que lo pueda acompañar, es capaz de producir cambios significativos en el proceso de aprendizaje y en el ambiente general de la comunidad educativa, ya que si existe una buena gestión existe el apoyo correspondiente por parte de la comunidad. Por otra parte, Arana (1998) opina sobre los componentes que intervienen en la gestión de la educación, de los cuales menciona que:

(...) hay muchos componentes o elementos que forman parte de la gestión educativa en la escuela. Dada la importancia que tiene cada uno en sí mismo, no debemos descuidar su formación ya que los procesos de gestión son el conjunto de acciones de planeamiento, organización, dirección de la ejecución, control y evaluación, necesarios para el eficiente desarrollo de la acción educativa. (p. 77)

En este entorno, los componentes que forman parte del proceso de gestión de la educación deben sustentar y evaluar su acción, como medio estratégico para la sostenibilidad de las políticas educativas en el centro educativo, sin menospreciar ninguno de ellos, ya que todos son importantes en la gestión de calidad.

Para Sovero (2007), los procesos de gestión en el centro educativo requieren una serie de elementos para llevar a cabo una buena acción directiva, entre los cuales están:

La planificación prevé la programación, ejecución y evaluación curricular. Se efectúa durante el mes anterior a la iniciación del año lectivo y sus producción el PDI y / 0 Plan Anual de Trabajo; este último se va desarrollando año a año dentro del cauce del PEI. (p. 61)

No obstante, la planificación es fundamental en los procesos de gestión de un centro educativo, ya que es una herramienta estratégica para el logro de los objetivos institucionales. La planificación permite al profesional que ejerce la gestión institucional llevar a cabo el desarrollo 
de sus funciones con eficiencia, eficacia y desarrollando todos los objetivos propuestos en su plan de trabajo. Además, permite la identificación de debilidades y errores que se comenten en el proceso de gestión.

En lo que refiere a la coordinación, se considera como un componente estratégico de la gestión porque reconoce la ejecución de los procesos educativos, en su momento. Al respecto, Lépiz (1999) considera los mecanismos de coordinación como una sincronización de las diferentes actividades involucradas en el acto de gestión, al mencionar que:

El establecimiento y mantenimiento de la armonía entre las actividades de los subsistemas de una dependencia o institución (...) "Con la coordinación se persigue sincronizar y unificar los esfuerzos y actividades desarrolladas para conseguir la unidad de acción en el logro de los objetivos propuestos. Los elementos fundamentales son la unidad de esfuerzos que se realicen. (p. 88)

La coordinación busca establecer y mantener un ambiente de armonía en las diferentes actividades y etapas de desarrollo dentro de las instituciones educativas, donde se espera ofrecer beneficios unificados a los esfuerzos y actividades desarrolladas por el personal docente, para el logro de los objetivos propuestos. Esto solo se logra con la unificación de los miembros que componen el personal que labora en la institución.

Los mecanismos de evaluación también son fundamentales en los procesos de gestión. A criterio de Alfaro, Bolaños, Muñoz, Sandoval, Valladares y Vega (2011):

(...) la evaluación: valora si el conjunto de actividades, medios utilizados, resultados obtenidos han cumplido los objetivos propuestos. (...) emplea tres niveles: una evaluación antes, durante y después del proyecto, en otras palabras una evaluación constante, transversal en toda organización. (pp. 114-115)

De esta forma, la evaluación del desempeño docente debe valorar todas las actividades que estos desarrollan en su trabajo diario, como pertinencia para fomentar estrategias en las diferentes etapas identificadas en cada evaluación, esperando que al finalizar el proceso, se demuestre un excelente trabajo por parte del personal docente sin deficiencia y que permita el mejoramiento de la calidad educativa y de su trabajo profesional. 
Todos estos componentes de la gestión implican pertinencia, la cual se concibe como el cumplimiento del papel que el proceso de evaluación docente y otras acciones deben desempeñar, en relación con lo que se espera de él, lo que requiere imparcialidad política y ética en su proceder profesional (Villaseñor, 2004).

Por su lado, las estrategias de organización conllevan la capacidad de "saber hacer"; es aplicar el uso racional de los recursos disponibles y gestionar al personal docente y administrativo para alcanzar los proyectos organizacionales.

Dentro de los requerimientos que conllevan al desarrollo de sus funciones cotidianas, está la capacidad de organizar y racionalizar los recursos disponibles con que cuenta la institución, no dejando por fuera en la toma de decisiones al personal docente y administrativo, en lo que corresponde al proceso de evaluar, sistemáticamente, la práctica pedagógica, de manera que esta incida en el mejoramiento del proceso enseñanza y aprendizaje en el centro educativo.

El control forma parte del proceso administrativo del mismo modo que la planeación, la organización y la dirección, por lo que se estudia como la cuarta función de los profesionales en administración de la educación que asegura que los resultados de aquello que se planeó, organizó y dirigió, se ajusten tanto como sea posible a los objetivos establecidos. De esta forma, la esencia del control reside en comprobar si la actividad controlada consigue o no los objetivos o los resultados esperados.

El control es, fundamentalmente, un proceso que guía la actividad ejecutada hacia un fin determinado. Como proceso, el control presenta etapas, tal como lo expresa, Chiavenato (2006), al mencionar que el control es un proceso cíclico compuesto de cuatro fases, por lo que "establece un proceso estándar o criterio; de la observación del desempeño; comportamiento de desempeño con el estándar de acciones correctas" (pp. 151-152). En el proceso de administración, los profesionales que desempeñan funciones de dirección en los centros educativos, deben tener la capacidad de llevar a cabo un buen control en la planeación, organización y dirección del proceso de evaluación del desempeño docente, ejecutándose según los objetivos establecidos en busca de los resultados esperados, por medio de la observación del comportamiento de desempeño según lo esperado en las organizaciones educativas o bien identificando las deficiencias y debilidades que éste presenta, para buscar el mejoramiento de las mismas y su fortalecimiento.

\section{Evaluación del desempeño docente.}

De acuerdo con la filosofía de la Ley Fundamental de Educación (1957), la evaluación del desempeño del personal docente en el aula es un juicio competente, realizada por los profesionales en administración de la educación en los centros educativos; en el cual se valoran 
actitudes, rendimientos y comportamiento laboral del personal en la ejecución de sus funciones, en términos de oportunidad, cantidad y calidad de los servicios que presta a su estudiantado.

La evaluación docente, por tanto, es un proceso dirigido a describir y notificar la forma en que se está desempeñando el trabajo en el aula, con el fin de elaborar planes de mejora para incrementar la calidad en el proceso de aprendizaje.

Cuando se realiza la evaluación del desempeño docente, se hace saber lo que se está evaluando y lo que se espera con esa acción, para que esto influya en el esfuerzo que se realice en busca de un adecuado desempeño, incidiendo en las tareas en el aula y en la mejora del rendimiento profesional.

Esta también sirve para comprobar las necesidades de formación y desarrollo profesional o refrescamiento de nuevas técnicas en el desempeño laboral docente, con el fin de fomentar la mejora de resultados, en función del como están desempeñando sus puestos y así, proponer los cambios necesarios en relación con el trabajo, la actitud, habilidades o conocimientos de los profesionales en educación.

Al respecto, Chiavenato (1998) define la evaluación del desempeño como un conjunto dinámico por el cual se evalúa, ya sea de manera formal o informal, el trabajo realizado por las personas en la organización. Este proceso evaluativo contribuye a encontrar los problemas relacionados con la supervisión de personal, la integración y el aprovechamiento docente, entre otros.

De esta forma, la evaluación del desempeño docente tiene como objetivo establecer normas, medir la ocupación de los mismos y buscar un mejoramiento de las funciones, para que el profesional en gestión directiva de la educación, reconozca el desempeño de su personal docente para fomentar el cuestionamiento positivo acerca de la necesidad de supervisión, con el fin de programar planes y objetivos para el mejoramiento del desempeño docente.

La evaluación es importante para reconocer las fortalezas y debilidades del personal docente, conocer su anuencia en la calidad de colaboración, en funciones y establecimiento equitativo en su desempeño. Este proceso permite determinar y comunicar al personal docente la forma en que están desempeñando sus funciones, para que se implementen planes de mejora que fomenten nuevos y mejores futuros resultados.

Al respecto, Casal-Gago (1998) refieren al papel de la evaluación del desempeño docente en la enseñanza que se imparte, donde "(...) el profesor establece una práctica reflexiva continuada de su enseñanza" (p. 89). De esta manera, el profesional en educación, a través de las distintas técnicas de evaluación, aplique una práctica reflexiva con información específica para mejorar su práctica docente. Por ello, la evaluación del desempeño docente es fundamental para que las organizaciones educativas monitoreen la calidad educativa que ofrecen. 


\section{Metodología}

El presente estudio se apoya en la investigación descriptiva utilizando técnicas cuantitativas y cualitativas para la presentación y análisis de datos. Emplea técnicas de ambos enfoques con el propósito de recopilar la opinión de los sujetos informantes, en este caso, entre el personal docente y administrativo de las organizaciones en estudio, con el fin de indagar sobre la evaluación del desempeño docente desde el proceso de gestión empleado. Para ello, se sistematiza la información, se organiza y ofrece un referente explicativo sobre las inquietudes y la problemática del objeto de estudio.

La población está conformada por el total del personal docente de las instituciones seleccionadas, así como de los profesionales en administración de la educación de las mismas, dando un total general de 53 docentes y dos direcciones. Esta información implica para la Escuela Limoncito, un total de 41 docentes y un profesional en administración de la educación y para la Escuela Los Lirios, 12 docentes y una persona encargada de la dirección.

La información fue recopilada mediante un cuestionario aplicado al personal docente y una entrevista a las personas que ocupan las direcciones de los centros educativos, a partir de las siguientes categorías de análisis que orientan el desarrollo de la investigación:

1. Planificación del proceso de evaluación del desempeño docente.

2. Coordinación del proceso de evaluación del desempeño docente.

3. Estrategias de organización ante el proceso de evaluación del desempeño docente.

4. Procedimientos empleados para el control en el proceso de evaluación del desempeño docente.

5. Mecanismos de evaluación del proceso de evaluación del desempeño docente.

6. Pertinencia el proceso de evaluación de desempeño docente.

\section{Análisis de la información}

\section{Caracterización de la población participante}

Los profesionales en administración de la educación de los centros educativos en estudio, poseen una trayectoria de más de veinte años de laborar para el Ministerio de Educación Pública y un promedio de siete años de ejercerse en el cargo directivo; su grado profesional es 
de Maestría en Administración Educativa y poseen la categoría profesional PT- $6^{2}$. El personal docente que labora para ambas instituciones, en su minoría, ostentan el grado profesional de Maestría con énfasis en I y II ciclo, con categoría profesional de PT-6, con una experiencia laboral de diez años en el sistema educativo costarricense; en su mayoría laboran en propiedad.

Otro grupo de ocho docentes, posee el grado profesional de Licenciatura en I y II ciclo, con categoría de PT-6 y su experiencia laboral es de diez años en propiedad. Otro grupo de seis docentes, posee el grado profesional de Bachiller en I y II ciclo, con categoría de PT- $5^{3}$. Asimismo, cinco docentes cuentan con el Diplomado en I y II ciclo, por lo que pertenecen al grupo profesional PT- $4^{4}$ y cuatro docentes, indican tener el grado académico de Diplomado en I y II ciclo, con categoría de grupo profesional PT-35. Estos docentes del nivel de Diplomado, poseen una experiencia laboral de diez años y están en propiedad.

\section{Planificación del proceso de evaluación del desempeño docente.}

La planificación de la evaluación del desempeño, según Díaz-Barriga (2006), implica la definición de los objetivos organizacionales, determinando donde se realizan éstos, desarrollando las primicias, considerando situaciones futuras e identificando y escogiendo entre cursos alternativos de acción; además, poniendo en marcha los planes de evaluar los resultados. La planificación del proceso del desempeño docente se indagó en este estudio mediante los siguientes indicadores:

- Articulación con la definición de objetivos organizacionales y el proceso de evaluación docente.

- Resultados de la evaluación del desempeño se consideran en situaciones futuras conlleve en la mejora docente según la planificación del centro educativo.

- Ejecución del proceso de desempeño docente según alternativas de acción en el plan institucional.

2 El grupo profesional PT-6 es una clasificación de categorías profesionales que realiza el Servicio Civil, instancia que se encarga de los nombramientos docentes, y le otorga esta categoría a los profesionales que poseen el grado académico igual o superior a la licenciatura en el campo de la educación.

3 El grupo profesional PT-5 es una clasificación de categorías profesionales que realiza el Servicio Civil, instancia que se encarga de los nombramientos docentes, y le otorga esta categoría a los profesionales que poseen el grado académico de Bachilleres en el campo de la educación.

4 El grupo profesional PT-4 es una clasificación de categorías profesionales que realiza el Servicio Civil, instancia que se encarga de los nombramientos docentes, y le otorga esta categoría a los profesionales que poseen el grado académico de diplomado en el campo de la educación.

5 El grupo profesional PT-3 es una clasificación de categorías profesionales que realiza el Servicio Civil, instancia que se encarga de los nombramientos docentes, y le otorga esta categoría a los profesionales que poseen el grado académico de diplomado en el campo de la educación. 
- Actitud negativa o positiva del docente frente a la evaluación de su desempeño interfiere con la planificación institucional del proceso del desempeño docente. (desconfianza, temor, inseguridad, arbitrariedad, subjetividad de irracionalidad y de poder autoritario/ un acto valioso, fructífero y deseable que le conlleve a mejorar la calidad profesional.

- La planificación del proceso de evaluación del desempeño docente toma en cuenta los resultados de manera que contribuyan con el dominio pedagógico autonomía sobre los contenidos, métodos, técnicas, elaboración de estrategias de enseñanza, capacidad para la organización de contextos de aprendizaje, habilidad para favorecer procesos de construcción de conocimientos según la heterogeneidad de los alumnos.

- La evaluación del desempeño docente ofrece información para tomar decisiones relacionadas con la promoción y con la elaboración de planes de mejoramiento del desempeño según lo planificado al respecto.

En este campo, la investigación determinó que el $72.41 \%$ del personal docente asume este proceso con una actitud positiva y consideran que conlleva a mejorar la calidad profesional. Estos hallazgos son importantes en el sentido de que se tiene, de parte del personal docente, una valoración positiva de los procesos de desarrollo académico, los cuales son considerados como medios para propiciar la mejora de su calidad docente, lo que le permitiría a la gestión de estos centros educativos, un mayor desarrollo de los procesos de planificación en torno a la mejora docente. En general, la apreciación positiva de esos procesos, coincide con la opinión de Chiavenato (2006), en el sentido que la evaluación del desempeño docente es un medio para encontrar problemas asociados a la supervisión del personal.

Una mayoría del personal docente consultado (68.96\%), opina que estos procesos desarrollan habilidades que favorecen procesos de construcción del conocimiento de acuerdo con la heterogeneidad del alumnado; precisamente, este es un aspecto fundamental que el sistema educativo espera en su apreciación y que para los profesionales en gestión de la educación viene a representar una ventaja organizacional, en aras del cumplimiento de los objetivos educativos. Asimismo, la planeación de la evaluación del desempeño del personal docente permite dar un seguimiento del trabajo en el aula, como lo indica Montero (2011) al considerar este proceso importante para el rendimiento laboral, para lo que indica que es criterio de cada organización evaluar en un momento adecuado y con el método que considere, variando según el puesto.

En este sentido, los profesionales en administración de la educación, deben desarrollar la evaluación del desempeño docente con el propósito de mejorar el rendimiento de los miembros de su organización, en los momentos oportunos, llevando consigo los pasos que le permite llevar este proceso, según el puesto y desempeño que se realice, de manera eficiente y oportuna. 
Poco más de la mitad (58.62\%), lo asumen como una alternativa de acción con respecto al plan institucional y un $55.17 \%$ del personal docente, considera que estos resultados apoyan la mejora del área pedagógica en cada docente. Finalmente, el 55.17\% del personal, confirma que éste permite la toma de decisiones para la promoción y elaboración del plan institucional, según lo proyectado. En general, los resultados son positivos para considerar de parte de los profesionales en administración de la educación, por lo que se pueden obtener provecho de los procesos, de manera que fundamenten la toma de decisiones en la promoción del plan institucional.

Las personas que ejercen la dirección en los centros educativos en estudio, coinciden en que la planificación del proceso de evaluación del desempeño docente, es una herramienta que permite el éxito y desarrollo de las organizaciones que dirigen, puesto que indican que permiten medir, en forma positiva, las fortalezas de su centro educativo y en general, del personal docente que está a su cargo.

De esta manera, se evidencia el proceso como un medio de mejorar el desarrollo profesional y el desempeño laboral que realiza el personal docente en sus salones de clase y dentro de su institución. Al respecto, Arroyo (2003) hace referencia a este proceso como una forma de medir el rendimiento real de cada uno de los miembros del personal, de acuerdo con una serie de estrategias por la descripción y significado del puesto. Asimismo, considera este proceso importante, ya que ofrece información base para la toma de decisiones, la promoción y remuneración en relación con el trabajo y la elaboración de planes y mejoramiento en el desempeño.

Así, la planificación del proceso de evaluación del desempeño docente representa una guía de acción por parte de la gestión del centro educativo, para tomar decisiones en aras del desarrollo de su personal docente; estrategias de importancia para el logro de los objetivos y metas en los centros educativos.

Ante este contexto, le corresponde a la administración de la educación realizar, periódicamente, evaluaciones informales en diferentes períodos y en su momento, evaluaciones formales a cada uno de los miembros de su personal, con el fin de mejorar las dificultades y desechar las conductas negativas o las debilidades en cuanto a su rendimiento profesional. Es importante tomar en cuenta que la planificación del proceso de la evaluación docente conlleva la aplicación de una serie de pasos que se deben tomar en cuenta, para que sea exitoso, como definir objetivos de la organización y su relación con los mismos, considerar situaciones futuras, así como también, identificar y escoger alternativas de acción y de esta forma, llegar a la ejecución de los planes para evaluar los resultados (Díaz-Barriga, 2006).

La siguiente figura, ilustra los hallazgos que el estudio evidenció con respecto al proceso de planificación en mención. Esta información se sustenta en el criterio externado por quienes ocupan la dirección del centro educativo y el personal docente de estos centros: 


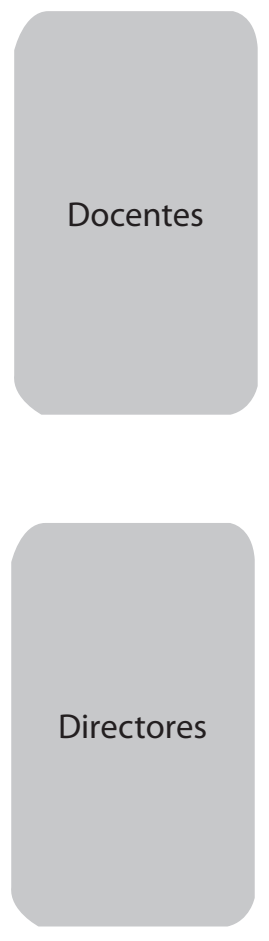

- Asume el proceso con una actitud positiva (72.41\%)

- Conlleva a mejorar la calidad profesional (72.41\%)

Desarrolla habilidades para favorecer procesos de construcción de conocimiento, según

la heterogeneidad de los alumnos(as). (68.96\%)

- Se considera como una alternativa de acción según el plan institucional. (158.62\%)

- Considera los resultados en mejora del área pedagógica de cada docente (55.17\%)

Permite la toma de desiciones para la promoción y elaboración de planes según la

planificación de la institución (55.17\%)

Figura 1. Planeación del proceso de evaluación del desempeño docente en Escuela Barrio Limoncito y Escuela Los Lirios, Circuito 02, Dirección Regional de Educación de Limón

Fuente: Cuestionarios aplicados a docentes y entrevista a las direcciones de las Escuelas Barrio Limoncito y Los Lirios, de la Dirección Regional de Limón, 2012.

Ante la planificación del proceso de evaluación del desempeño docente, desde la administración de la educación y tomando en cuenta el rol de los profesionales en la gestión de la misma, es importante el abordaje preventivo por medio de un sistema de evaluación del desempeño docente que manifieste a los funcionarios lo que se espera de ellos, con el fin de llenar las expectativas y obtener seguridad en lo que deben hacer, a partir de una adecuada gestión de mejora.

\section{Mecanismos de coordinación en la evaluación docente.}

La coordinación de la evaluación del desempeño docente, se refiere al establecimiento y mantenimiento de la armonía entre las actividades de los subsistemas de una dependencia o institución, por los cuales se busca sincronizar y unificar esfuerzos y desarrollar actividades para conseguir la unidad de acción en el logro de los objetivos planteados (Lépiz, 1999). Un centro educativo que mantiene una buena coordinación en sus mecanismos de planificación para 
la evaluación del desempeño docente, tiene altas posibilidades de ser exitoso y mantener un personal satisfecho en sus funciones educativas. Los indicadores que permitieron profundizar en el estudio sobre los mecanismos de coordinación en la evaluación docente son:

- Establecer y mantener las partes involucradas en forma armoniosa entre las actividades que se requieren para su ejecución.

- Unificar y sincronizar esfuerzos de parte del director del centro educativo para llevar a cabo el proceso.

- Consolidar acciones y logros necesarios para llevar a cabo el proceso en aras del desarrollo de la institución.

- Los miembros de la institución realizan esfuerzos para alcanzar los fines propuestos del proceso.

Sobre esta categoría la investigación determinó que, a criterio del personal docente (62.06\%), en gran medida se refuerzan las acciones y logros necesarios para llevar a cabo el proceso, en aras del desarrollo institucional. Un 58.62\% considera que se manifiesta la unificación y sincronización de esfuerzos por parte de los profesionales que ejercen la dirección de los centros educativos para llevar a cabo el proceso de evaluación del desempeño docente, permitiendo una función exitosa.

Reviste de importancia que, en general, se considera que el personal docente trabaja reforzando acciones para implementar el proceso por el bien de la institución, aunque si se debe trabajar, en forma más ardua, en unificar esfuerzos por parte de la dirección, en torno a este proceso de evaluación del desempeño docente, puesto que es una tarea importante de la gestión de las organizaciones educativas encauzar sus esfuerzos para armonizar, desde la coordinación, para que el proceso de evaluación del desempeño docente se lleve a cabo en forma adecuada e incida en el desarrollo del personal docente y finalmente, pueda el proceso de enseñanza aprendizaje darse con mayor eficiencia.

La organización eficiente a través de una buena administración de la institución, ejerce un control adecuado de la organización, como lo expone Chiavenato (2006) al interpretar los objetivos organizacionales y desplegarlos en forma organizada, en acciones mediante la planeación, la organización la dirección y el control, con el fin de lograr los objetivos propuestos.

Los hallazgos determinaron que, el $42.27 \%$ del personal docente, considera que se establecen y mantiene, entre las partes involucradas, en forma armoniosa, las actividades que se requieren para la ejecución del proceso de evaluación del desempeño docente; para un $42.27 \%$ del personal docente, los miembros de la institución realizan esfuerzos para alcanzar los fines propuestos del proceso. Estos evidencian una mayor necesidad de un trabajo armonioso en conjunto y mayores esfuerzos para alcanzar lo que se estipula en la evaluación del desempeño docente, tarea que le corresponde liderar a los profesionales directivos de los centros educativos, tal y como lo exponen Koontz y Weihrich 
(1994), al atribuirle a la administración un papel esencial para asegurar la coordinación de los esfuerzos individuales; entre más complejas sean las organizaciones, esta tarea es fundamental.

Toda organización tiene que poseer una gerencia que lidere el buen funcionamiento; es imperativo que todos los integrantes se interesen por ello, puesto que esta tarea se logra mediante adecuados procesos de coordinación, lo cual se espera en los profesionales en administración de la educación para que la evaluación del desempeño docente mejore los resultados académicos. La dirección de estos centros educativos considera, con respecto a los mecanismos de evaluación del desempeño docente, que se trabaja en armonía con todo el personal docente involucrado en las actividades necesarias para la ejecución del proceso de enseñanza-aprendizaje dentro de la institución. El personal docente, en ese sentido, realiza esfuerzos de forma unificada y sincronizada y trabaja para el alcanzar los fines propuestos del proceso, consolidan las acciones y logros necesarios para llevar a cabo el proceso, en aras del desarrollo de la institución. La siguiente figura ilustra los principales hallazgos del estudio con respecto a los mecanismos de coordinación empleados en el proceso de evaluación del desempeño docente:
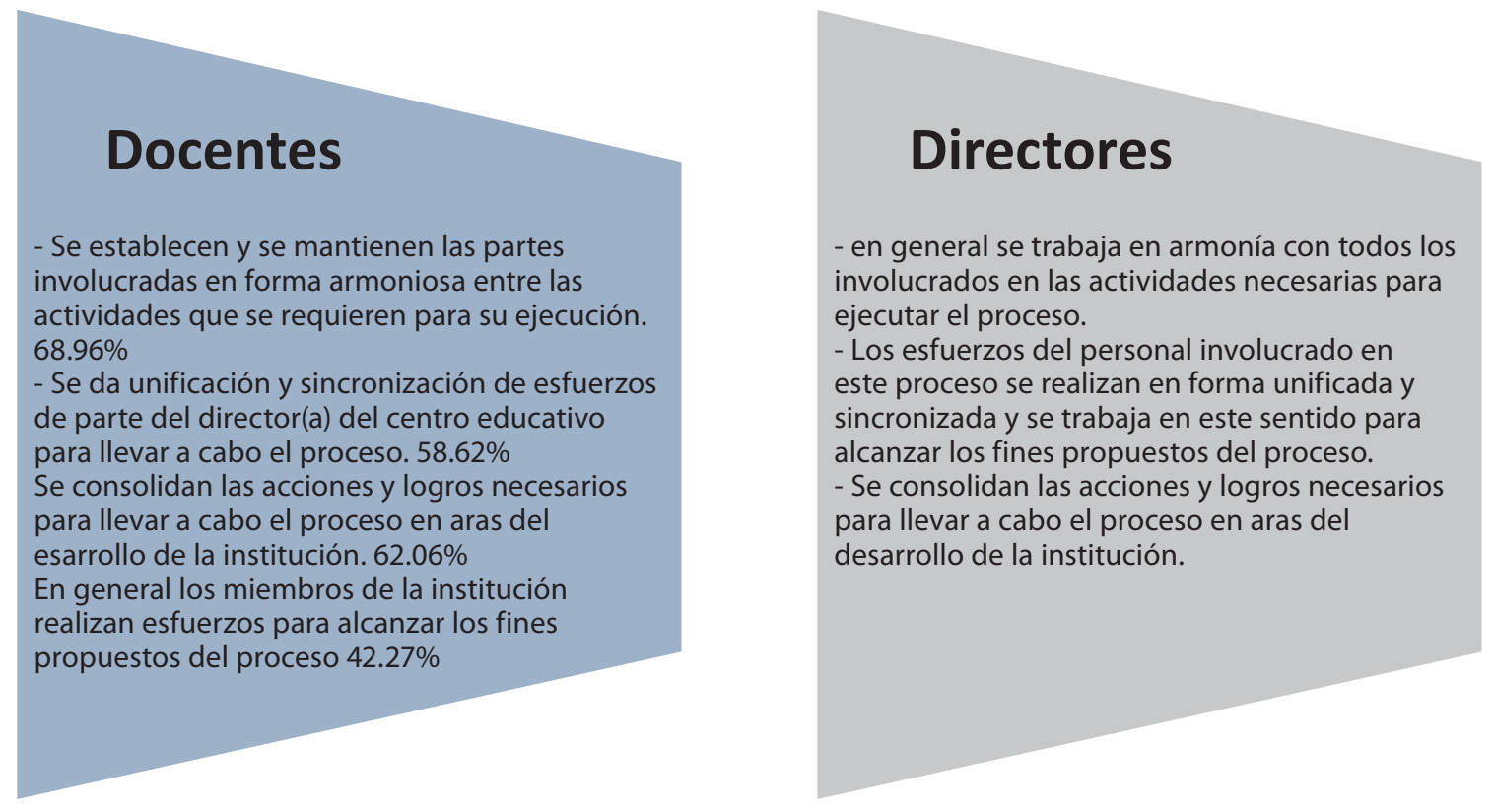

Figura 2. Coordinación del proceso de evaluación del desempeño docente Escuela Barrio Limoncito y Escuela Los Lirios, Circuito 02, Dirección Regional de Educación de Limón

Fuente: Cuestionarios aplicados a docentes y entrevista a las direcciones de las Escuelas Barrio Limoncito y Los Lirios, de la Dirección Regional de Limón, 2012.

\begin{tabular}{|c|c|c|}
\hline Marianela Ugalde Vega & Número publicado el 30 de Diciembre del 2012 \\
\hline
\end{tabular}


La importancia para la administración de la educación de establecer adecuados mecanismos de coordinación en la puesta en práctica del proceso de evaluación del desempeño docente, es fundamental para que éste se lleve a cabo según los parámetros establecidos por las instancias reguladoras e involucradas en el desempeño docente; a su vez, son procesos que vienen a coadyuvar en el desarrollo profesional docente, lo que constituye un aspecto estratégico para el éxito de toda organización educativa.

\section{Estrategias de organización en la evaluación docente.}

Las instituciones educativas tienen la tarea de implementar la organización, sujeta a adecuados controles con todos los medios disponibles, como lo son materiales y el recurso humano del cual dispone el centro educativo. Estos controles se manifiestan en los procesos de evaluación del desempeño docente mediante planeamientos teóricos específicos y sistemáticos, donde se establece una organización escolar bajo el orden práctico de los distintos elementos de los centros educativos. Se toma en cuenta dentro de la función de organización, los contextos de aprendizaje que favorezcan procesos de construcción de conocimientos, según las particularidades del alumnado. De esta manera, es importante construir y evaluar, sistemáticamente, sus prácticas pedagógicas para las que la evaluación del desempeño académico es fundamental (Ministerio de Educación Pública de Perú, 2012).

Con el propósito de indagar sobre la organización de los procedimientos de la evaluación del desempeño docente, se partió de los siguientes indicadores:

- Uso racional de los recursos materiales disponibles para aplicar el proceso.

- Uso racional de los recursos financieros disponibles para aplicar el proceso.

- Uso racional del personal docente disponible para aplicar el proceso.

- Uso racional del personal administrativo disponible para aplicar el proceso.

La investigación permitió conocer que la mayoría del personal docente (68.96\%) de las instituciones en estudio, considera que se da un uso racional del recurso humano disponible para aplicar el proceso de evaluación del desempeño docente. Asimismo, el $62.18 \%$ reconoce que se da un uso racional de los recursos y materiales disponibles para aplicar el proceso y cerca de la mitad de la población docente consultada (55.12\%), 
manifiesta un uso racional también de los recursos financieros disponibles para aplicar el proceso. Se evidencia que hay un uso racional aceptable, considerando que la aplicación de la evaluación del desempeño conlleva una serie de recursos institucionales para su desarrollo. Precisamente, es utilizando estrategias de organización que se conlleva a esta capacidad de saber hacer y aplicar, en forma racional, los recursos disponibles y gestionar al personal docente para alcanzar los proyectos organizacionales (Garbanzo y Orozco, 2007).

Sobre este tema, quienes ocupan la dirección de estos centros educativos, consideran que los mecanismos de organización para llevar a cabo la evaluación del desempeño docente se acompaña de un uso racional de los recursos materiales, financieros, personal docente y administrativo, lo que incide en forma positiva en el desempeño docente y el proceso de enseñanza - aprendizaje impartido, en la medida que los profesionales en educación, como parte de la organización de este proceso en forma anticipada, se les da a conocer los mecanismos sobre los cuales se sustenta el proceso de evaluación del desempeño.

Sobre la importancia de la organización en estos procesos, Fernández y Sarramona (1997) consideran que en el ambiente escolar debe darse una articulación entre sus elementos, de manera que se ofrezcan múltiples relaciones entre sí, en concordancia con sus objetivos, donde el alumnado y personal docente articulen sus esfuerzos por los intereses institucionales. En este campo, es fundamental una buena organización entre todos sus componentes, adecuando los medios y recursos necesarios. Esta información se detalla seguidamente, en la Figura 3.

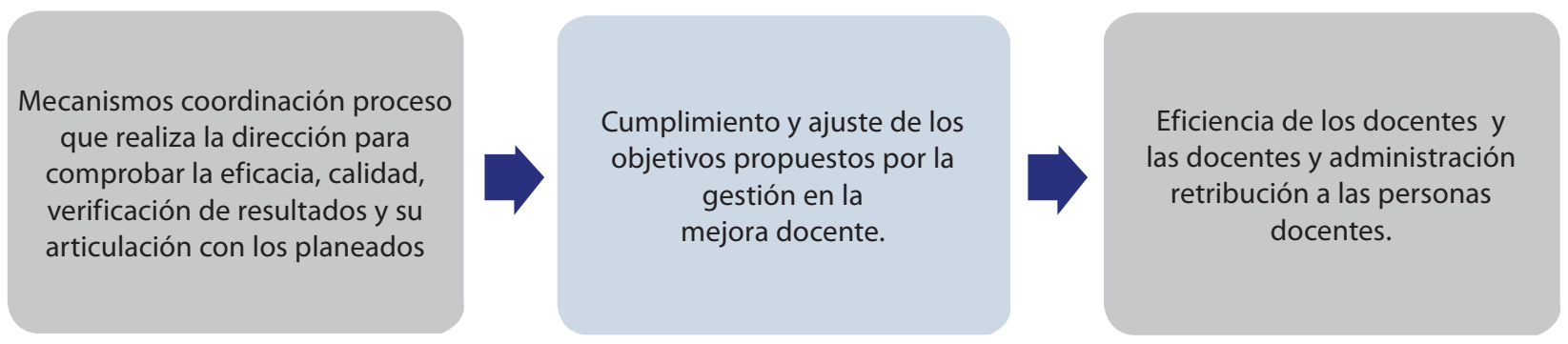

Figura 3. Estrategias de organización referentes al uso de los recursos en la evaluación del desempeño docente, Escuela Barrio Limoncito y Escuela Los Lirios, Circuito 02, Dirección Regional de Educación de Limón

Fuente: Cuestionarios aplicados a docentes y entrevista a las direcciones de las Escuelas Barrio Limoncito y Los Lirios, de la Dirección Regional de Limón, 2012. 
La opinión favorable del personal docente supera más de la mitad de la población, por lo que estos resultados no alcanzan una opinión superior al $63 \%$, lo que hace pensar en la necesidad de fortalecer estrategias de organización, desde la gestión de los centros educativos, para explotar en forma racional, los recursos disponibles que un proceso como este implica. En la medida que las estrategias de organización se fortalezcan, es posible encontrar mejores resultados en el desempeño docente, de manera que los objetivos institucionales se alcancen con mejor calidad. Los procesos que buscan la mejora docente, a su vez, desean la calidad de la educación, razón por la cual los administradores de la educación debe comprender que más una evaluación, la institución debe organizar este proceso con el fin de articularlo en la mejora de los objetivos institucionales, alcanzando en gran medida los fines y objetivos de la educación costarricense.

\section{Procedimientos empleados para el control en la evaluación del desempeño docente}

El control forma parte del proceso administrativo, del mismo modo que la planeación, organización y dirección. Este se estudia como la cuarta función del proceso administrativo, ya que el control asegura que los resultados de lo que se planea, organice y dirige se ajuste tanto como sea posible a los objetivos establecidos. De ahí, que la esencia del control reside en comprobar si la actividad controlada consigue o no los objetivos o los resultados esperados.

El control es, fundamentalmente, un proceso que guía la actividad ejecutada hacia un fin determinado. El control es un proceso cíclico compuesto del establecimiento de un proceso estándar o criterio; observación del desempeño; comportamiento de desempeño con el estándar acciones correctas (Chiavenato, 2006).

Por esa razón, se indagó sobre el procedimiento utilizado en los centros educativos para el control del proceso de evaluación del desempeño docente, para lo cual se parte de los siguientes indicadores:

- Adecuada verificación del cumplimiento del proceso de evaluación del desempeño docente de parte de la dirección.

- Mecanismos de control para verificar que el proceso de evaluación docente se ajuste a los objetivos que lo sustentan.

- Mecanismos gestados en el proceso de evaluación del desempeño para el logro de los objetivos planteados. por la dirección. 
- Mecanismos de gestión que se ajuste a lo establecido por la organización en el control del proceso de evaluación del desempeño educativa, en la mejora del desempeño docente.

La investigación permitió conocer que el $65.51 \%$ del personal docente considera que existen mecanismos gestados por la dirección para controlar el proceso de evaluación del desempeño y poder así, lograr los objetivos planteados. El $62.06 \%$ opina que estos mecanismos gestados por la dirección se ajustan a lo establecido por la organización educativa en la mejora docente; para cerca de la mitad de la población (51.17\%), la dirección lleva a cabo una adecuada verificación del cumplimiento del proceso de evaluación del desempeño docente. Una porcentaje similar (51.17\%), considera que existen mecanismos de control por parte de la dirección para verificar que el proceso se ajuste a los objetivos que lo sustentan.

La información evidencia que se aplican controles en este proceso, de forma que se lleve a cabo de manera adecuada la evaluación del desempeño docente. Sin embargo, la opinión de la existencia de estos controles no supera el $66 \%$ de la población, datos que tomando en cuenta la importancia de este proceso, se esperaría que fueran más altos. En esta medida, los procesos que evalúan el desempeño docente deben ir acompañados de controles por parte de la gestión, lo que constituye una tarea fundamental de los profesionales en administración de la educación, a quienes le corresponde velar por el adecuado funcionamiento institucional, en aras de los objetivos propuestos. Al respecto, hay que tomar en cuenta que el control es un proceso cíclico compuesto de fases, cuya aplicación secuencial determina el proceso adecuado, de acuerdo con los estándares establecidos (Chiavenato, 2006).

Por su parte, quienes ejercen la dirección de los centros educativos consideran que los mecanismos de coordinación empleados en la evaluación del desempeño docente, por parte de la dirección, permiten una adecuada verificación del cumplimiento del proceso en las organizaciones educativas. Estos mecanismos, por lo general, se acompañan de visitas de los profesionales en administración de la educación a las aulas, estadísticas, así como revisiones de documentos en forma constante. Estas estrategias son fundamentales para apoyar la gestión de las organizaciones educativas, asegurado el funcionamiento de la institución escolar (Antúnez y Aranguren, 1998). Las organizaciones educativas deben asegurar, desde la gestión, la implementación de adecuados controles para verificar si se cumplen los objetivos propuestos en el plan institucional. Esta se ilustra en la siguiente figura. 


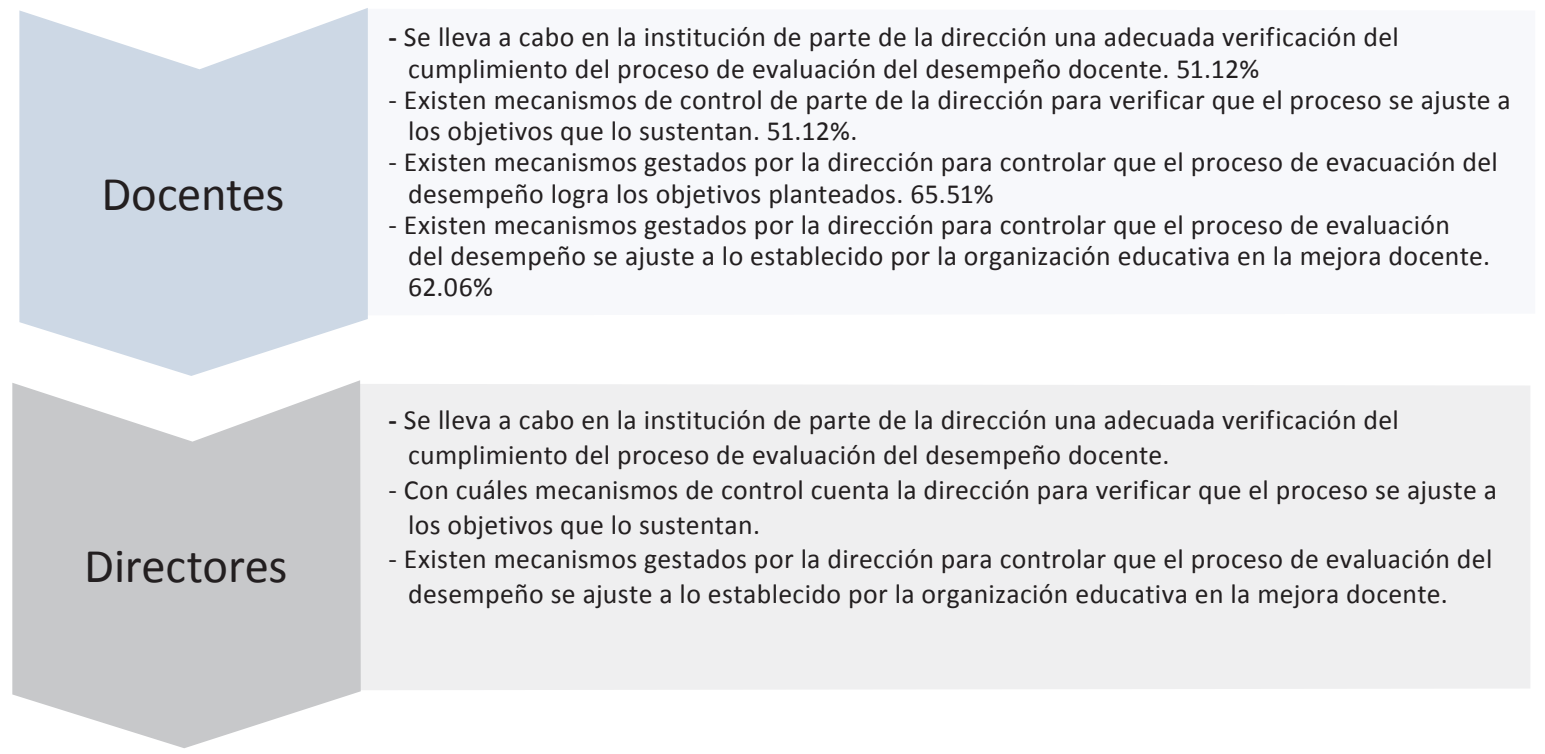

Figura 4. Implementación de controles en el proceso de evaluación del desempeño docente, Escuela Barrio Limoncito y Escuela Los Lirios, Circuito 02, Dirección Regional de Educación de Limón

Fuente: Cuestionarios aplicados a docentes y entrevista a las direcciones de las Escuelas Barrio Limoncito y Los Lirios, de la Dirección Regional de Limón, 2012.

Con respecto a los mecanismos de control en ambas instituciones, se evidencia la necesidad de mejorarlos en torno a la implementación del proceso de la evaluación del desempeño docente emanado por el Ministerio de Educación Pública, con el fin de obtener los resultados según el propósito por el cual fue creada.

\section{Mecanismos de evaluación del proceso de evaluación del desempeño docente.}

No es posible aspirar a una visión general del avance de los objetivos propuestos en el plan institucional sin una adecuada evaluación de sus alcances y limitaciones, razón por la cual la administración de la educación debe incorporar en sus planes de trabajo los criterios bajo los cuales evaluará su desempeño institucional. Al respecto, considera D’Agostino (1995) que en las organizaciones educativas se necesitan procesos oportunos para la comprobación de la eficiencia y calidad de los distintos componentes que interaccionan para la realización del acto educativo, con el fin de valorar su cumplimiento de acuerdo con los parámetros establecidos para la toma de decisiones. 
De esta forma, la evaluación busca la valoración del conjunto de actividades, medios utilizados, así como los logros alcanzados, en articulación con el cumplimiento de los objetivos propuestos, para lo que se apoya, a criterio de Alfaro et al. (2011), en una evaluación constante, a lo largo de los diferentes proyectos que se llevan a cabo en la organización. Sustentado en lo anterior, se presenta el siguiente estudio acerca de los mecanismos del proceso de la evaluación desempeño docente, fundamentado en los siguientes indicadores:

- Mecanismos utilizados para comprobar la eficacia y calidad del proceso de evaluación del desempeño docente por parte de la gestión.

- Mecanismos para verificar si los resultados del proceso de evaluación del desempeño docente son consecuentes con lo planeado por la dirección.

- Resultados del proceso de evaluación del desempeño docente representan insumos para la toma de decisiones.

- El proceso de evaluación del desempeño docente se acompaña de una medición antes, constante y después de la ejecución.

Los hallazgos de la investigación permitieron determinar que, a criterio del 68.96\% del personal docente, existen mecanismos de parte de la dirección de las instituciones para comprobar la eficacia y calidad del proceso; para un $65.51 \%$, se cuenta con mecanismos implementados por la dirección para verificar si los resultados del proceso de evaluación del desempeño docente son consecuentes con lo planeado. Un 62.06\%, considera que los resultados de este proceso de evaluación del desempeño docente representan insumos para la toma de decisiones y, para cerca de la mitad de la población (51.17\%), se acompaña de una medición antes, durante y después de la ejecución. En general, se visualiza que, en ambas instituciones, se implementan mecanismos de evaluación para verificar el cumplimiento de este proceso, lo que demuestra que la gestión tiene claridad en que la evaluación del desempeño docente debe acompañarse de acertados procesos que puedan monitorear los avances y limitaciones que se van alcanzando, con el fin de mejorar el proceso educativo que tienen a cargo.

De esta manera, le corresponde a la administración velar por el sano cumplimiento de los objetivos de la educación costarricense, para lo cual es indispensable contar con profesionales que se desenvuelvan en forma adecuada, con capacidad para reconocer sus debilidades y encausar su desarrollo profesional con alto nivel profesional. Sobre este tema, Chiavenato (1998) considera que la evaluación del desempeño es como un conjunto dinámico, que permite al personal que labora en las organizaciones ser evaluados, ya sea de manera formal o informal; lo anterior, es precisamente lo que busca la gestión de estas organizaciones educativas, en aras de la excelencia académica. 
Por su parte, la dirección de los centros educativos en estudio, considera que realizan estrategias para comprobar la eficacia, calidad, verificación de resultados y su articulación; a su vez, lo consideran como insumos para la toma de decisiones, acompañada de una medición antes, durante y después de su ejecución. Criterio que coincide con Arana (1998), quien indica que para lograr una buena gestión educativa, se deben crear las condiciones necesarias para su cumplimiento, con autoridades que promuevan y potencien sistemas de participación y comunicación, de manera que la comunidad educativa cumplan con funciones para lograr las metas y objetivos sobre los que han tomado acuerdos, como es el caso de la evaluación del desempeño docente, responsabilidad indiscutiblemente, a cargo de los gestores de la educación. Esta información se representa en la siguiente figura.

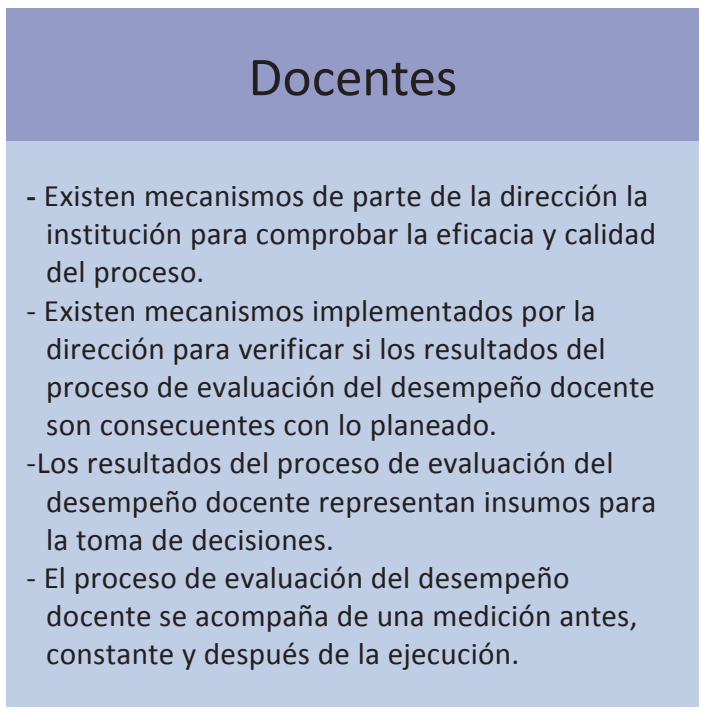

\title{
Directores
}

\author{
- Mecanismos de parte de la dirección del proceso \\ para comprobar la eficacia, calidad, verificación de \\ resultados y su articulación con los planeados. \\ - Resultados del proceso de evaluación del \\ desempeño docente representan insumos para la \\ toma de desiciones. \\ -El proceso de evaluación del desempeño docente \\ se acompaña de una medición antes, constante y \\ después de la ejecución.
}

Figura 5. Mecanismos de evaluación del desempeño docente Escuela Barrio Limoncito y Escuela Los Lirios, Circuito 02, Dirección Regional de Educación de Limón

Fuente: Cuestionarios aplicados docentes y entrevista a las direcciones de las Escuelas Barrio Limoncito y Los Lirios, de la Dirección Regional de Limón, 2012.

Con respecto a los diferentes mecanismos de evaluación aplicados al proceso de evaluación del desempeño docente, es importante considerar el papel de la gestión para que estos procesos cuenten con adecuados criterios evaluativos y apoyar la mejora docente, en beneficio ante la población estudiantil.

\section{Pertinencia del proceso de evaluación docente.}

La pertinencia se concibe como el papel que el proceso de evaluación docente debe desempeñar, en relación con lo que se espera de éste en el desarrollo de su función, lo que requiere 
imparcialidad política y ética en su proceder (Villaseñor, 2004). La evaluación del desempeño docente se valora como un acto productivo que incide en la calidad de la educación, mediante el uso de distintas estrategias que fortalezcan la labor docente. La pertinencia de la evaluación del desempeño docente implica calidad, tanto de los profesionales en administración de la educación como en el personal docente, de manera que se fortalezca el proceso educativo, en aras del beneficio estudiantil, lo que se traduce en mejores estrategias pedagógicas, docentes con acertados niveles de autonomía sobre los contenidos, métodos, técnicas y elaboración de estrategias de enseñanza, de acuerdo con la heterogeneidad del estudiantado; solo así, se podría considerar que estos procesos de evaluación del desempeño docente sean pertinentes.

La pertinencia de estos procesos evaluación de desempeño, también, toma en cuenta la organización de contextos de aprendizaje y procesos de construcción de conocimientos, según las particularidades del contexto en el que se desarrolla, De esta manera, es importante construir y evaluar, sistemáticamente, sus prácticas pedagógicas (Ministerio de Educación Pública de Perú, 2012).

Bajo este contexto, se indagó sobre la pertinencia del proceso de evaluación del desempeño docente con los siguientes indicadores:

- Responde el proceso de evaluación del desempeño docente a los objetivos por el cual se implementó.

- Imparcialidad política.

- Visión ética.

El estudio determinó que el $58.62 \%$ del personal docente considera que este proceso responde a los objetivos por los cuales se implementó; menos de la mitad de la población (44.84\%), opina que se aplica con imparcialidad política y una población similar (42.27\%), manifiesta que se aplica con una visión ética. Los profesionales en administración de la educación de estos centros educativos, coinciden con el personal docente al considerar que el proceso de evaluación del desempeño docente responde a los objetivos por los que fue creado, por lo que se aplica con imparcialidad política y ética.

Se evidencia contradicción entre la opinión del personal docente y las direcciones, puesto que no es ni la mitad de la población docente la que ve este proceso con parcialidad política y ética, elementos que de no darse, ponen en duda la pertinencia de este costoso mecanismo de evaluación para medir el desempeño docente en las instituciones educativas. Por ello, es importante tomar en cuenta que toda evaluación requiere alejarse de cualquier nivel de parcialidad que permita dudar de su credibilidad; de ahí, que Chiavenato (1998) define la evaluación del desempeño como un conjunto dinámico, donde los miembros de la organización son evaluados por distintos medios, formales e 
informales. Este proceso evaluativo contribuye a atinar los problemas de la supervisión de personal, la integración y el aprovechamiento del personal docente.

De esta forma, la evaluación del desempeño docente tiene como objetivo establecer normas, medir el desempeño de los mismos y así, indagar un mejoramiento de las funciones de manera positiva, para que los profesionales encargados de la gestión directiva de la educación, reconozcan el desempeño del personal docente a su cargo, por lo que deben fomentar los cuestionamientos positivos acerca de la necesidad de supervisión, con el fin de que se programen planes y objetivos para el mejoramiento del desempeño docente.

Al respecto, la gestión de las organizaciones educativas debe prestar atención a la evaluación del desempeño docente, con el fin de que se logre implementar la misma con altos niveles de objetividad, de manera que el personal docente encuentre en estos procesos, un medio de crecimiento profesional, de lo contrario, tanto los esfuerzos como los recursos destinados serían en vano.

También, llama la atención que solo una población que representa un 58.62\%, encuentra, considera que este proceso se articulación con los objetivos para los cuales fue creado; datos de consideración, si lo que se quiere es fortalecer la calidad de la educación mediante el acertado desempeño docente. Esta información se indica en la siguiente figura.

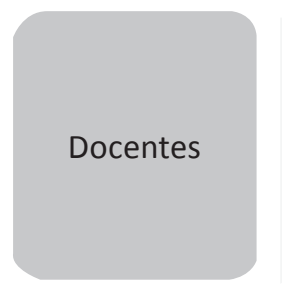

- El proceso de evaluación del desempeño docente responde a los objetivos por los cuales se implementó

- La evaluación del desempeño docente, se aplica con imparcialidad política.

- La evaluación del desempeño docente, se aplica con una visión ética.

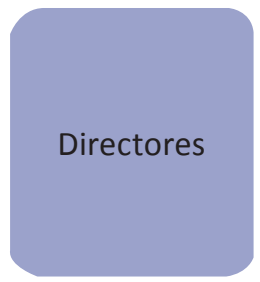

\footnotetext{
El proceso de evaluación del desempeño docente responde a los objetivos por los cuales se implementó

El proceso de evaluación del desempeño docente, se aplica con imparcialidad política y ética.
}

Figura 6. Pertinencia del proceso de evaluación docente en la Escuela Barrio Limoncito y Escuela Los Lirios, Circuito 02, Dirección Regional de Educación de Limón

Fuente: Cuestionarios aplicados a docentes y entrevista a las direcciones de las Escuelas Barrio Limoncito y Los Lirios, de la Dirección Regional de Limón, 2012. 
En general, los procesos de evaluación del desempeño docente requieren acompañarse de adecuados procesos de gestión de la educación, de manera que se fortalezca su pertinencia en aras de la calidad educativa.

\section{Reflexión final}

La investigación pone en evidencia, una vez más que, para el sistema educativo, los procesos de evaluación del desempeño son fundamentales para mejorar el desarrollo del desempeño docente, en busca de la calidad de la educación que se imparte. Es indispensable, por ello, contar con adecuados procesos como la gestión de las organizaciones educativas que permitan fortalecer estos procesos.

Ante estos hallazgos, fue posible encontrar debilidades desde la gestión para la implementación del proceso de evaluación del desempeño docente, que merecen ser retomados ante la necesidad de implementar adecuados mecanismos que orienten este desarrollo docente y que fortalezcan su pertinencia, de manera que represente realmente un medio para su crecimiento profesional, aplicándose con ética y parcialidad política; principales reclamos de parte del personal docente.

La planificación del proceso de la evaluación docente conlleva la aplicación de una serie de pasos que se deben tomar en cuenta desde la gestión para que sea exitoso, como definir objetivos de la organización y su relación con estos, considerando situaciones futuras, así como también, identificar y escoger alternativas de acción que permitan la ejecución de los planes para evaluar los resultados. De ahí, que la mayoría del personal docente considera que el proceso de planificación de evaluación del desempeño docente se asume con una actitud positiva para la mejora de la calidad profesional docente. El hecho de que este proceso es valorado en forma positiva, facilita la labor de gestión y un mayor desarrollo de los procesos de planificación, en torno a la mejora docente.

La planeación de la evaluación del desempeño del personal docente, por tanto, permite dar un seguimiento del trabajo en las aulas, acción que debe ser desarrollada por los profesionales en administración de la educación, con el propósito de mejorar el rendimiento de los miembros de su organización, en forma oportuna. Como proceso, debe aplicarse mediante pasos precisos, en aras de la eficiencia docente.

En los centros educativos en estudio, con respecto al proceso de planificación del desempeño docente, cerca de la mitad de los consultados lo consideran una alternativa de acción con respecto al plan institucional y un porcentaje similar, considera que estos resultados apoyan la mejora del área pedagógica en cada docente. Además, se le atribuye su capacidad 
de apoyar la toma de decisiones para la promoción y elaboración del plan institucional, según lo proyectado. Por su lado, los profesionales en administración de la educación de estos centros educativos, consideran que la planificación del proceso de evaluación del desempeño docente es una herramienta que permite el desarrollo de sus instituciones educativas, para medir en forma positiva, las fortalezas organizacionales y en general, del personal docente que está a su cargo.

Con respecto a la coordinación de la evaluación del desempeño docente, queda clara la importancia, desde la gestión institucional, de sincronizar, unificar esfuerzos y desarrollar, en forma adecuada, la implementación del proceso de evaluación del desempeño docente. El estudio pudo determinar que, en gran medida, a criterio del personal docente, se refuerzan las acciones y logros necesarios para llevar a cabo el proceso, para el desarrollo de la institución. De igual manera, el personal docente considera que se manifiesta la unificación y sincronización de esfuerzos por parte de las direcciones de los centro educativo para llevar a cabo el proceso de evaluación del desempeño docente, permitiendo una función exitosa. De esta forma, la administración de la educación es primordial para establecer adecuados mecanismos de coordinación que permitan el desarrollo del proceso de evaluación del desempeño docente, de acuerdo con los parámetros establecidos por las instancias reguladoras e involucradas en el desempeño docente.

Con respecto al control implementado por la gestión para llevar a cabo el proceso de evaluación del desempeño docente, su esencia reside en comprobar si la actividad controlada consigue o no los objetivos o resultados esperados. En el caso específico de este estudio, se evidenció que el personal docente considera que existen mecanismos gestados por la dirección para controlar el proceso de evaluación del desempeño y así, poder lograr los objetivos planteados. Además, opinan que estos mecanismos se ajustan a lo establecido por la organización educativa en la mejora docente, por lo que se lleva a cabo una adecuada verificación del cumplimiento del proceso de evaluación del desempeño docente, de forma que responda a los objetivos que lo sustentan.

Los hallazgos de la investigación permitieron determinar que, a criterio del personal docente, existen mecanismos de parte de la dirección de las institución para comprobar la eficacia y calidad del proceso; a su vez, se cuenta con mecanismos implementados por la dirección para verificar si los resultados del proceso de evaluación del desempeño docente son consecuentes con lo planeado y que los resultados representan insumos para la toma de decisiones, por lo que se acompaña de una medición antes, durante y después de la ejecución.

La pertinencia de la evaluación del desempeño docente implica calidad profesional, tanto de los profesionales en administración de la educación como del personal docente, de manera que se fortalezca el proceso educativo en aras del beneficio estudiantil. Lo anterior, se traduce en mejores estrategias pedagógicas por parte de docentes con acertados niveles de autonomía 
sobre los contenidos, métodos, técnicas y elaboración de estrategias de enseñanza, de acuerdo con la diversidad que se presenta en las aulas.

Al respecto, el estudio determinó que el personal docente considera que el proceso de evaluación del desempeño docente es pertinente para las funciones que éstos ejercen y con la evaluación institucional y los objetivos por los cuales se implementó. Asimismo, es menos de la mitad del personal docente el que opina que se aplica con imparcialidad política y con una visión ética. Los profesionales en administración de la educación de los centros educativos en estudio, coinciden con el personal docente en que el proceso de evaluación del desempeño docente, responde a los objetivos por los que fue creado y se aplica con imparcialidad política y ética.

\section{Referencias}

Airasian, E. y Gullickson, D. (2000). Herramientas de auto y mutua evaluación del profesorado. España: Ediciones Mensajero.

Alfaro, D., Abraham, J., Erazo, I., Bolaños, F., Him, C., Muñoz, L., Sandoval, J., Valladares, W. y Vega, A. (2011). Guía para la autoevaluación de programas académicos en la educación superior. España: Sicevaes.

Antúnez, A. y Aranguren, C. (1998). Aproximación teórica y epistemológica al problema de evaluación. Su condición en educación básica. Boletín técnicas y didácticas de las Ciencias Sociales, (3), pp. 104-117. Facultad de Humanidades y Educación. Universidad de los Andes. Venezuela. Recuperado de http://www.saber.ula.ve/bitstream/123456789/23925/1/bol3 angel antunez.pdf

Arana, M. (1998). Principios y procesos de la gestión educativa. (Colección pedagógica). Lima, Perú: Editorial San Marcos.

Argudín, Y. (2006). Educación basada en competencias. México: Trillas.

Arroyo, J. A. (2003). Administración del personal docente en las instituciones educativas. San José, Costa Rica: Universidad de Costa Rica.

Asamblea Legislativa de la República de Costa Rica. (1957). Ley Fundamental de Educación. Ley 2160. San JoséCostaRica.Recuperado dewww.mep.go.cr/.../DOC/leyfundamental-285200810525. pdf

Blank, B. (1990). La administración de organizaciones, un enfoque estratégico. Cali, Colombia: Centro Editorial Universidad del Valle. 
Díaz-Barriga, Á. (2006). El enfoque de las competencias en la educación. ¿Una alternativa o un disfraz de cambio? Perfiles educativos, 28(111), 7-36. Recuperado de http://redalyc.uaemex. $\mathrm{mx} / \mathrm{src} /$ inicio/ArtPdfRed.jsp?iCve=13211102

Casal, S. y Gago, M. (1998). La evaluación del proyecto curricular. Andalucía: Asociación de profesores de Escuela Oficial de Idioma.

Chacón, L., Elizondo, Y., Fernández, M., Triana, J. y Umaña, E. (2011). Abordaje docente y administrativo de los conflictos estudiantiles en el campo de la educación secundaria. Revista Gestión de la Educación, 1(1),1-29. Recuperado de http://revistadigital.eae.fcs.ucr. ac.cr/index.php/component/content/article/3/42-abordaje-docente-y-administrativo-delos-conflictos-estudiantiles-en-el-campo-de-la-educacion-secundaria.html

Chiavenato, I. (1998). Administración de recursos humanos. Colombia: McGraw-Hill.

Chiavenato, I. (2006). Introducción a la teoría general de la educación. México: McGraw-Hill Interamericana.

D’Agostino, G. (1995). Aspectos teóricos de la evaluación educacional. San José, Costa Rica: EUNED.

Delors, J., Mufti, I., Amagi, I., Carneiro, R., Chung, F., Geremek, B. y Nanzhao, Z. (1996). La educación encierra un tesoro. Informe a la UNESCO de la Comisión Internacional sobre educación para el siglo XXI (Compendio). Francia: Santillana Ediciones.

Fernández, A. y Sarramona, J. (1997). La educación. Constantes y problemática actual. Vía layetana, 17(3). Barcelona, España.

Garbanzo, G. y Orozco, V. H. (2007). Desafíos del sistema educativo costarricense: Un nuevo paradigma de la administración de la educación. Revista Educación, 27(1), 95-110. Recuperado de http://www.latindex.ucr.ac.cr/educacion-31-2/06-GARBANZO.pdf

Gutiérrez, F. (1982). Educación como praxis política. San José, Costa Rica: Siglo XXI Editores. Recuperado de www.sigloxxieditores.com

Koontz, H. y Weihrich, W. (1994) Elementos de administración moderna. Bogotá: McGraw-Hill.

Lépiz, C. (1999). Diseñar y enseñar. Madrid: Marceva.

Ministerio de Educación Pública de Perú. (2012). La evaluación del desempeño docente a criterio del Ministerio de Educación Pública de Perú. Recuperado de http://www.sumaeducacion.pe/ pdf/plan_piloto.pdf

Montero, L. (marzo, 2011). El trabajo colaborativo del profesorado como oportunidad formativa. CEE 
Participación Educativa, 16, 69-88. Universidad de Santiago de Compostela. Recuperado en: http://www.educacion.gob.es/revista-cee/pdf/n16-montero-mesa.pdf

Romero, C. (2004). La escuela media en la sociedad del conocimiento. Buenos Aires: Noveduc.

Salazar, R. (1998). La gestión de los administradores educativos de primaria del circuito 10 de San José en torno a la calidad de la educación en Costa Rica. (Tesis de Licenciatura). Universidad de Costa Rica. San José, Costa Rica.

Sovero, F. (2007). Organización y funciones de las instituciones educativas, instrumentos de gestión. En S. Franklin. Gestión educacional. Tomo I Gestión administrativa Lima, Perú: Editorial Palomino.

Villaseñor, G. (2004). La sociedad del conocimiento y la pertinencia de la educación superior, vistas desde América Latina. En L. Mota y J. Cisneros (Comps). La educación superior en América Latina. Globalización, exclusión y pobreza (pp. 40-53). Recuperado de http://books. google.es/books?id=Ex0oK_zoHagC\&printsec=frontcover\&hl=es\&source=gbs_ge_summ ary_r\&cad=0\#v=onepage\&q\&f=false 
Anexo A

Cuestionario dirigido a docentes

Estimado(a) señor (a):

El presente cuestionario tiene como objetivo identificar su opinión acerca del proceso de evaluación del desempeño docente que se lleva a cabo en las organizaciones educativas del Ministerio de Educación Pública.

Se le solicita su colaboración para responder a cada una de las preguntas planteadas. La información que usted brinde será completamente confidencial.

Gracias por su valiosa colaboración.

\section{INFORMACIÓN DEL PARTICIPANTE}

Instrucciones: Marque con una "X" (equis) la opción acorde con su respuesta.

\section{Formación Académica}

$\begin{array}{llllll}\text { Diplomado } & \text { ( ) } & \text { Licenciatura } & \text { ( ) } & \text { Doctorado } & \text { ( ) } \\ \text { Bachillerato } & \text { ( ) } & \text { Maestría } & \text { ( ) } & \text { Ninguna } & \text { ( ) }\end{array}$

\section{Años de experiencia profesional}

De 1 a 5 () De 5 a 10 () De 10 en adelante ()

\section{Condición laboral}

Propiedad ( ) Interino( )

\section{Categoría Profesional:}

$\begin{array}{llclclclll}\text { Aspirante } & (\text { ) } & \text { PAU1 } & (\text { ) } & \text { PAU2 } & (\text { ) } & \text { PAU 3 } & (\text { ) } & \text { PT6 } & \text { ( ) } \\ \text { PT2 } & (\text { ) } & \text { PT3 } & (\text { ) } & \text { PT4 } & (\text { ) } & \text { PT5 } & (\text { ) } & & \end{array}$

\section{PROCESO DE EVALUACIÓN DEL DESEMPEÑO DOCENTE}

Instrucciones: Marque con una " $\mathrm{X}$ " (equis) la opción acorde con su respuesta, según los enunciados que se le presenta a continuación.
1. Siempre
2. A veces
3. Nunca 


\begin{tabular}{|c|c|c|c|c|}
\hline \multicolumn{2}{|r|}{ Con respecto a la planificación del proceso de evaluación del desempeño docente } & \multirow[t]{2}{*}{1} & \multirow[t]{2}{*}{2} & \multirow[t]{2}{*}{3} \\
\hline 1. & Considera usted que articula los objetivos con lo proyectado en el plan institucional. & & & \\
\hline 2. & $\begin{array}{l}\text { Considera usted que los resultados conllevan a la mejora en situaciones futuras enmarcadas } \\
\text { en la planificación institucional del centro. }\end{array}$ & & & \\
\hline 3. & Se considera como una alternativa de acción según el plan institucional. & & & \\
\hline 4. & A nivel personal asume el proceso con una actitud negativa. & & & \\
\hline 5. & A nivel personal asume el proceso con una actitud positiva. & & & \\
\hline 6. & Interfiere en forma positiva con la planificación institucional. & & & \\
\hline 7. & Interfiere en forma negativa con la planificación institucional. & & & \\
\hline 8. & Conlleva a mejorar la calidad profesional. & & & \\
\hline 9. & Considera los resultados en mejora del área pedagógica de cada docente. & & & \\
\hline 10. & $\begin{array}{l}\text { Contribuye a incrementar la autonomía del docente en su ejercicio laboral en: contenidos, } \\
\text { métodos, técnicas, elaboración de estrategias de enseñanza, capacidad para la organización } \\
\text { de contextos de aprendizaje. }\end{array}$ & & & \\
\hline 11. & $\begin{array}{l}\text { Desarrolla habilidad para favorecer procesos de construcción de conocimientos según la } \\
\text { heterogeneidad de los alumnos. }\end{array}$ & & & \\
\hline 12. & $\begin{array}{l}\text { Permite la toma de decisiones para la promoción y elaboración de planes según la planifica- } \\
\text { ción de la institución. }\end{array}$ & & & \\
\hline \multicolumn{2}{|r|}{ Con respecto a la coordinación del proceso de evaluación del desempeño docente } & 1 & 2 & 3 \\
\hline 13. & $\begin{array}{l}\text { Se establecen y se mantiene las partes involucradas en forma armoniosa entre las actividades } \\
\text { que se requieren para su ejecución. }\end{array}$ & & & \\
\hline 14. & $\begin{array}{l}\text { Se da unificación y sincronización de esfuerzos de parte del director del centro educativo } \\
\text { para llevar a cabo el proceso. }\end{array}$ & & & \\
\hline 15. & $\begin{array}{l}\text { Se consolidan las acciones y logros necesarios para llevar a cabo el proceso en aras del desa- } \\
\text { rrollo de la institución. }\end{array}$ & & & \\
\hline 16 & $\begin{array}{l}\text { En general los miembros de la institución realizan esfuerzos para alcanzar los fines propues- } \\
\text { tos del proceso. }\end{array}$ & & & \\
\hline \multicolumn{2}{|r|}{ Con respecto a las estrategias de organización y el proceso de Evaluación del desempeño docente } & 1 & 2 & 3 \\
\hline 17. & Se da un uso racional de los recursos materiales disponibles para aplicar el proceso. & & & \\
\hline 18. & Se da un uso racional de los recursos financieros disponibles para aplicar el proceso. & & & \\
\hline 19. & Se da un uso racional del personal docente disponible para aplicar el proceso. & & & \\
\hline 20. & Se da un uso racional del personal administrativo disponible para aplicar el proceso. & & & \\
\hline
\end{tabular}




\begin{tabular}{|c|c|c|c|c|}
\hline & $\begin{array}{l}\text { Con respecto a los procedimientos empleados para el control ante el proceso de } \\
\text { Evaluación del Desempeño Docente }\end{array}$ & 1 & 2 & 3 \\
\hline 21. & $\begin{array}{l}\text { Se lleva a cabo en la institución de parte de la dirección una adecuada verificación del cum- } \\
\text { plimiento del proceso de evaluación del desempeño docente }\end{array}$ & & & \\
\hline 22. & $\begin{array}{l}\text { Existen mecanismos de control de parte de la dirección para verificar que el proceso se ajuste } \\
\text { a los objetivos que lo sustentan. }\end{array}$ & & & \\
\hline 23. & $\begin{array}{l}\text { Existen mecanismos gestados por la dirección para controlar que el proceso de evaluación del } \\
\text { desempeño logra los objetivos planteados. }\end{array}$ & & & \\
\hline 24. & $\begin{array}{l}\text { Existen mecanismos gestados por la dirección para controlar que el proceso de evaluación } \\
\text { del desempeño se ajuste a lo establecido por la organización educativa en la mejora docente. }\end{array}$ & & & \\
\hline Con & respecto a los mecanismos de evaluación del proceso de evaluación del Desempeño Docente & 1 & 2 & 3 \\
\hline 25. & $\begin{array}{l}\text { Existen mecanismos de parte de la dirección la institución para comprobar la eficacia y cali- } \\
\text { dad del proceso. }\end{array}$ & & & \\
\hline 26. & $\begin{array}{l}\text { Existen mecanismos implementados por la dirección para verificar si los resultados del proce- } \\
\text { so de evaluación del desempeño docente son consecuentes con lo planeado. }\end{array}$ & & & \\
\hline 27. & $\begin{array}{l}\text { Los resultados del proceso de evaluación del desempeño docente representan insumos para } \\
\text { la toma de decisiones. }\end{array}$ & & & \\
\hline 28. & $\begin{array}{l}\text { El proceso de evaluación del desempeño docente se acompaña de una medición antes, } \\
\text { constante y después de la ejecución. }\end{array}$ & & & \\
\hline & Con respecto a Pertinencia el proceso de evaluación de Desempeño Docente & 1 & 2 & 3 \\
\hline 29. & $\begin{array}{l}\text { Responde el proceso de evaluación del desempeño docente a los objetivos por el cual se } \\
\text { implementó. }\end{array}$ & & & \\
\hline 30. & Se aplica con imparcialidad política. & & & \\
\hline 31. & Se aplica con una visión ética. & & & \\
\hline
\end{tabular}


Anexo B

Entrevista dirigida a los directores

Estimado(a) señor (a):

La presente entrevista tiene como objetivo identificar su opinión acerca del proceso de evaluación del desempeño docente desde la gestión del centro educativo que usted lidera.

La información brindada es de uso confidencial.

Gracias por su valiosa colaboración.

I PARTE: INFORMACIÓN GENERAL DEL PARTICIPANTE

\section{Formación Académica}

$\begin{array}{llllll}\text { Diplomado } & \text { ( ) } & \text { Licenciatura } & \text { ( ) } & \text { Doctorado } & \text { ( ) } \\ \text { Bachillerato } & \text { ( ) } & \text { Maestría } & \text { ( ) } & \text { Ninguna } & \text { ( ) }\end{array}$

\section{Años de experiencia profesional}

De 1 a 5 () De 5 a 10 () De 10 en adelante ()

\section{Condición laboral}

Propiedad( ) Interino( )

\section{Categoría Profesional:}

$\begin{array}{llclclclll}\text { Aspirante } & (\text { ) } & \text { PAU1 } & \text { ( ) } & \text { PAU2 } & \text { ( ) } & \text { PAU 3 } & \text { ( ) } & \text { PT6 } & \text { ( ) } \\ \text { PT2 } & \text { ( ) } & \text { PT3 } & \text { ( ) } & \text { PT4 } & \text { ( ) } & \text { PT5 } & \text { ( ) } & & \end{array}$

\section{PARTE. PROCESO DE EVALUACIÓN DEL DESEMPEÑO DOCENTE}

Refiérase a la planificación del proceso de evaluación del desempeño docente y su articulación con el plan institucional. Tome en cuenta:

- Articulación de los objetivos,

- En qué medida los resultados conllevan a la mejora en situaciones futuras según la planificación institucional del centro.

- Es una alternativa de acción en toma de decisiones este proceso para la planificación institucional.

- Actitud del docente ante el proceso. 
- Interfiere este proceso en la planificación institucional, cómo lo hace.

- Los resultados conllevan a mejorar la calidad profesional, en lo pedagógico, autonomía docente, construcción de conocimientos según heterogeneidad de los alumnos. Cómo se articula con el proceso de planificación institucional todo esto.

\section{Con respecto a la coordinación del proceso de evaluación del Desempeño Docente refiérase a:}

- En general se trabaja en armonía con todos los involucrados en las actividades necesarias para ejecutar el proceso.

- Los esfuerzos del personal involucrado en este proceso se realizan en forma unificada y sincronizada y se trabaja en este sentido para alcanzar los fines propuestos del proceso.

- Se consolidan las acciones y logros necesarios para llevar a cabo el proceso en aras del desarrollo de la institución.

Con respecto a las estrategias de organización y el proceso de Evaluación del desempeño docente, refiérase a:

- Se da un uso racional de los recursos materiales, financieros, y del personal docente y administrativo para aplicar el proceso.

\section{Con respecto a los procedimientos empleados para el control ante el proceso de Evaluación del Desempeño Docente, refiérase a:}

- Se lleva a cabo en la institución de parte de la dirección una adecuada verificación del cumplimiento del proceso de evaluación del desempeño docente.

- Con cuáles mecanismos de control cuenta la dirección para verificar que el proceso se ajuste a los objetivos que lo sustentan.

- Existen mecanismos gestados por la dirección para controlar que el proceso de evaluación del desempeño se ajuste a lo establecido por la organización educativa en la mejora docente.

Con respecto a los mecanismos de evaluación del proceso de evaluación del Desempeño Docente, refiérase a:

- Mecanismos de parte de la dirección del proceso para comprobar la eficacia, calidad, verificación de resultados y su articulación con lo planeados.

- Resultados del proceso de evaluación del desempeño docente representan insumos para la toma de decisiones.

- El proceso de evaluación del desempeño docente se acompaña de una medición antes, constante y después de la ejecución.

\section{Con respecto a Pertinencia el proceso de evaluación de Desempeño Docente, refiérase a:}

- Responde el proceso de evaluación del desempeño docente a los objetivos por el cual se implementó.

- Se aplica con imparcialidad política y ética. 